\title{
UPDATING RECENT STUDIES ON THE SHROUD OF TURIN
}

\author{
ALAN D. ADLER
}

\begin{abstract}
The Shroud of Turin, a linen cloth alleged to be the burial shroud of Christ, has been precisely radiodated to the $14^{\text {th }}$ century. Nevertheless, its status remains controversial. Is the radiodate accurate? Are the blood images seen on the cloth derived from contact of the cloth with a wounded human body? Is it a painting? If not a painting, what is the mechanism of its formation? Some of the latest research attempting to resolve these matters is presented and reviewed.
\end{abstract}

The Shroud of Turin can be unequivocally historically traced to the mid- $14^{\text {th }}$ century. ${ }^{1}$ Because it was alleged at that time to be the authentic burial cloth of Christ, it has always been an object of controversy. This $4.3 \times 1.1 \mathrm{~m}$ linen cloth bears both complete head-to-head, frontal and dorsal, straw colored, "negative" body images of a crucified man with blood colored wounds and scourge marks in accordance with Biblical description of the Crucifixion. The body images are bracketed the entire length of the cloth by parallel burn and scorch marks from fire damage incurred in 1532. Waterstains from extinguishing this fire are also evident, as are patched areas from repairs carried out in 1534 prior to the entire cloth being stitched to a backing cloth (see note p. 86) to support the damaged original. There is a continuous seam along one side of the cloth producing a "side" strip with rectangular pieces of missing cloth at both ends of this strip. The main body of the cloth adjacent to these missing cloth areas shows selvage edges indicative of repair. There is no historic record of why or when this repair and seam were applied to the original cloth.

In 1978 a group of investigators, Shroud of Turin Research Project (STURP), carried out several on-site investigations of the Shroud at its repository in Turin and also took several sticky tape samples from designated areas of the cloth for further off-site studies. This work and the subsequent research has been summarized in several publications. ${ }^{2,4}$ STURP's major conclusions were that the Shroud was not a painting, the body image chromophore was an oxidation product of the cellulose of the linen fibers comprising the cloth, and the blood images were blood-derived materials produced from contact of the cloth with a wounded human body. A microscopical investigation of the STURP sticky tape samples by an independent investigator came to the opposite conclusion that the Shroud was a painting with the body images composed of iron oxide in a gelatin protein

First published in: Archaeological Chemistry: Organic, Inorganic, and Biochemical Analysis, Mary V. Orna ed., American Chemical Society Symposium Series, 625, Washington DC, 1996. 
binder and the blood images composed of the same pigment with the addition of considerable cinnabar (HgS) with traces of calcite, 5 commonly found components of medieval paint pigments. As it was clear that science could never authenticate the Shroud as the burial cloth of Christ, but could positively disauthenticate it, STURP strongly recommended and supported a radiocarbon dating test. ${ }^{4}$

\section{Radiocarbon Dating}

Three laboratories in a collaborative study independently radiodated samples from the Shroud of Turin by the Accelerator Mass Spectroscopy (AMS) method and reported a reasonably precise $14^{\text {th }}$ century date in apparent agreement with its unequivocally known historic record. ${ }^{6}$ Unfortunately, a detailed protocol for sampling the Shroud, assuring both precision and accuracy, recommended by a convened group of consultants, ${ }^{7}$ was not followed. Only a single sample was taken in the lower corner of the main cloth of the frontal image below the so-called sidestrip from the selvage edge in an obviously waterstained area just a few inches from a burn mark. The selvage edge was trimmed off before portions of the sample were divided among the participating laboratories. Whether such an obviously contaminated sample is truly representative of the rest of the cloth is clearly questionable and the accuracy of the reported date is certainly doubtful.

To assess this question we have carried out further spectroscopic investigations of samples from the STURP sticky tapes (Adler, Selzer, and DeBlase; technical details submitted for publication elsewhere). Nineteen assorted fibers representative of non-image, waterstain, scorch, image, backing cloth, and serum coated fibers were extracted from the tapes and characterized by previously reported methods. ${ }^{2}$ These were compared with fifteen single fibers taken from three threads from the radiocarbon sample. Similarly, two blood samples (previously designated as globs) were extracted from the tapes and compared against several types of blood controls. The blood controls included two simulacra: a traumatic blood clot exudate (whole blood diluted with bilirubin-enriched human albumin) and mineral simulated blood (iron oxide, cinnabar, and a trace of calcite suspended in gelatin). These samples were all examined by Fourier Transform Infrared (FTIR) microspectrophotometry and the fibers were also studied by scanning electron microprobe. Dried films of the two blood simulacra were also studied by Ultraviolet-Visible (UV-vis) spectrophotometry. Some typical FTIR spectral patterns of these samples from this study are shown in Figures 1 and 2.

The patterns seen in Figure 1 are all distinguishably different from one another clearly indicating differences in their chemical composition. These compositional differences were further confirmed by peak frequency analysis utilizing the computer software that generates the spectral data. In particular the radiocarbon samples are not representative of the nonimage samples that comprise the bulk of the cloth. This difference was also supported by the scanning electron microprobe data that showed gross enrichment of the inorganic mineral elements in the radiocarbon samples, even compared to the waterstain fibers taken from the bulk of the cloth. In fact, the radiocarbon fibers appear to be an exaggerated composite 


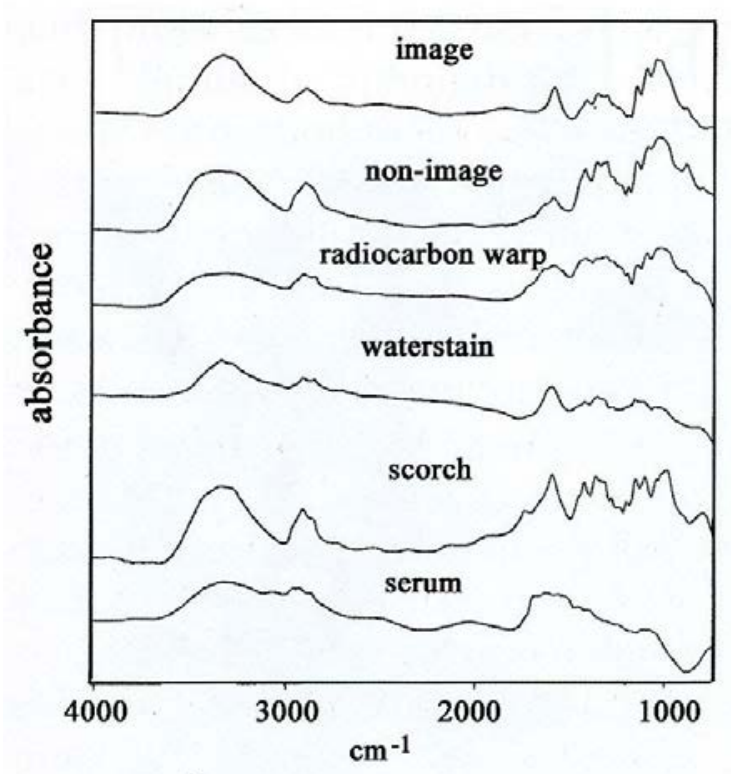

Fig. 1. Typical FTIR absorbance patterns of single fiber samples of the Shroud of Turin.

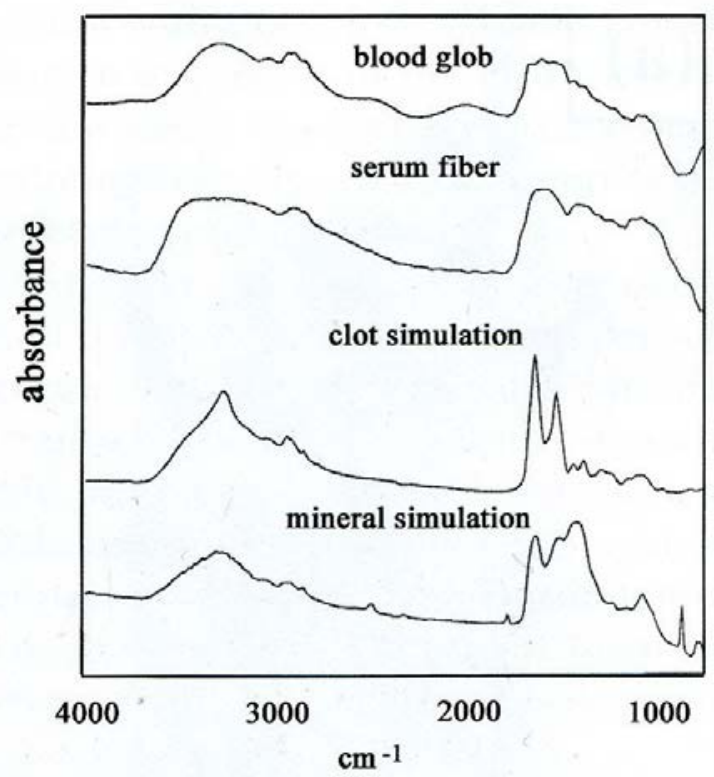

Fig. 2. Typical FTIR absorbance pattern of blood samples of the Shroud of Turin compared with blood simulacra.

of the waterstain and scorch fibers, thus confirming the physical location of the suspect radiosample site and demonstrating that it is not typical of the non-image sections of the main cloth. How much these differences in chemical composition actually affected the accuracy of the radiodate is not clear. However, these data are consistent with a recently proposed mechanism in which has been experimentally demonstrated that conditions comparable to those suffered by the Shroud in the 1532 fire can produce a large error in radiodating by large kinetic isotope effects. ${ }^{8}$ Alternatively, considering the presence of the selvage edge, this area may contain newly woven material as a repair.

Some recent image analysis studies comparing the blood marks on the Shroud of Turin with those on the Cloth of Oviedo also cast doubt on the accuracy of the Shroud's radiodate (Whanger, Duke University, personal communication, May 1994). The Cloth of Oviedo, alleged to be the sudarium associated with Christ's death, contains blood images similar in appearance to those on the Shroud, an can be historically traced to the $7^{\text {th }}$ century. ${ }^{9}$ In Figure 3 the equally scaled dorsal head wound marks on the two cloths are compared with one another. The similarity of these two complex patterns is evident enough to suggest that the two cloths were in contact with the same wounded body, presumably within the same short time period. Should further research reveal stronger relationship between these two relics, the accuracy of the $14^{\text {th }}$ century date of the Shroud will be clearly doubtful, as the Cloth of Oviedo is considered at least $7^{\text {th }}$ century.

\section{Blood Images}

Analysis of the FTIR data in Figure 2 compared with various controls show that bilirubin can be spectrally detected in both the blood samples and the yellow 

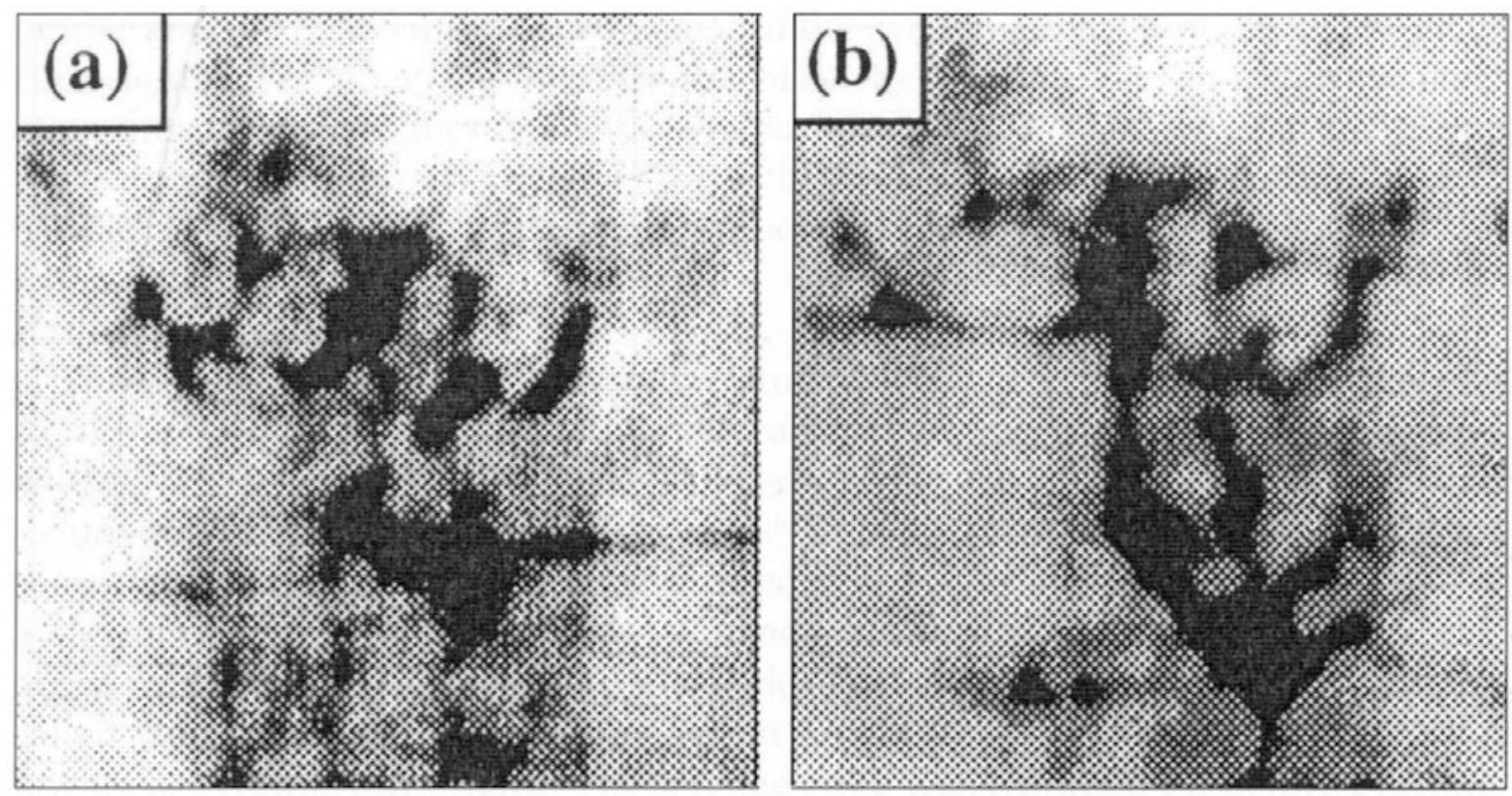

Fig. 3. Comparison of dorsal head wound marks on the Shroud of Turin (a) and the Cloth of Oviedo (b).

serum coated fibers in agreement with the previously reported chemical data. ${ }^{2}$ The pattern match of the simulated clot appears only fair, but spectral analysis utilizing the computer software shows that reducing the protein pattern and increasing the bilirubin pattern makes a very good fit to the blood sample pattern. Conversely, the mineral simulated blood pattern is a complete mismatch except for the presence of protein. Bilirubin is clearly required to obtain a proper spectral match.

The same conclusions are drawn from the near UV-vis spectra of the two simulacra. The clot simulation is in good agreement with the previously reported spectra of Shroud blood specimens and that taken from the on-site examination of the blood images on the whole cloth matching the observed peaks at 420, 450, 520, 580, and $630 \mathrm{~nm}^{10}$ Increasing the amount of bilirubin in this simulacrum will also improve the fit as with the FTIR data. However, the mineral blood simulation showing only two broad low peaks at 470 and $514 \mathrm{~nm}$ is again a complete mismatch. This is not surprising as it should be recalled that the two onsite X-ray examinations of the Shroud did not reveal the presence of any mercury compounds, particularly in the blood image areas. ${ }^{11,12}$ Thus these two new pieces of spectral evidence completely reinforce all the previous chemical, immunological, and forensic work demonstrating that the blood images on the cloth are blood-derived materials produced from contact of the cloth with clotted blood wounds on a human body ${ }^{2-4}$ and are not composed of an artist's applied mineral pigment mixture. ${ }^{5}$

\section{Body Images}

Peak frequency analysis of the FTIR data also shows that the image fibers contain more conjugated carbonyl absorption than the non-image fibers, consistent 
with previous identification of the chromophore with a cellulose oxidation product. $^{2,4}$ Similarly, although the spectral presence of protein in the characteristic amide absorption regions is readily seen on the serum fibers, it is not detectable on the image fibers, as stipulated by the painting hypothesis. This supports the previously published work refuting the painting hypothesis. ${ }^{2,4}$

Numerous copies of the Shroud of Turin exist and it has now been thoroughly historically documented that several of these painted copies were "sanctified" by being pressed to the original. ${ }^{13}$ This process would clearly contaminate the Shroud with artist's materials by contact transfer. Therefore it cannot be maintained that the Shroud is a painting simply on the basis of the microscopical detection of such materials ${ }^{5}$ in the face of the large corpus of evidence against such a simplified explanation ${ }^{2,4}$ The accumulated physical, chemical, and forensic data do not support the contention that the images on the Shroud of Turin are paintings. In particular, the image studies very clearly rule against this supposition. ${ }^{14}$

\section{Image Formation Mechanisms}

Establishing that the Shroud is not a painting still allows the possibility of its production by some other type of artistic rendition technique. However, many possible formation processes have been tested against the observed properties of this image and have all been found inadequate in some way if they are to be accepted as the explanation of this complex object. ${ }^{3 \text {, }}$ 14, 15 Image studies have shown that the body image and the blood images are not always in stereometric register. ${ }^{14,6}$ As the blood can only have been transferred onto the cloth by contact, this implies that the body images were produced by some type of non-contact mechanism. ${ }^{14}$ Some image studies ${ }^{14}$ would suggest some type of radiational or energy transfer type mechanism. However, the nature of this process at this point in time remains a mystery. This should not be interpreted as proof that the image was produced by some supernatural process, but simply reflects the present state of our knowledge of this interesting object. Hopefully, future studies will not only resolve this mystery, but will provide a sound basis for undertaking the preservation and conservation of this cloth and its images. ${ }^{17}$

\section{Acknowledgements}

I am indebted to several of my colleagues for help, information and advice in preparing this manuscript. Luke Adler of LA Engineering Computer Services prepared the figures and utilized photographic materials supplied by Drs. Gil Lavoie and Alan Whanger. 


\section{REFERENCES}

1. WILSON, I., The Mysterious Shroud; Doubleday \& Co., Inc.: Garden City, NY; 1986, pp. 1-156.

2. HELLER, J., ADLER, A., Can. Soc. Forens. Sci. J. 1981, 14, 81-103.

3. SCHWALBE, L., ROGERS, R. Anal. Chim. Acta 1982, 135, 3-49.

4. JUMPER, J., ADLER, A., JACKSON, J., PELLICORI, S., HELLER, J., DRUZIC, J., in: Archaeological Chemistry, Lambert, J. B., Ed., Advances in Chemistry 205; American Chemical Society: Washington, DC, 1984, pp. 447-476.

5. MCCRONE, W., Acc. Chem. Res. 1990, 23, 77-83.

6. DAMON, P., et. al., Nature 1989, 337, 611-615.

7. HARBOTTLE, G., HEINO, W., in Archaeological Chemistry-IV: Allen, R O., Ed., Advances in Chemistry 220; American Chemical Society: Washington, DC., 1989; pp. 313-320.

8. KOUZNETSOV, D., IVANOV, A., VELETSKY, V., Presented at the 209th National Meeting of the American Chemical Society, Anaheim, CA, April 1995; paper HIST 007.

9. RICCI, G., The Holy Shroud, Centro Romano di Sindonologia: Rome, Italy; 1981, pp 137-143.

10. HELLER, J., ADLER, A., Appl. Opt. 1980, 19, 2742-2744.

11. MOTTERN, R., LONDON, R., MORRIS, R., Materials Eval. 1980, 38, 39-44.

12. MORRIS, R., SCHWALBE, L., LONDON, J., X-ray Spectrometry 1980, 9, $40-47$.

13. FOSSATI, L., Shroud Spectrum Inter. 1984, 13, 23-39.

14. JACKSON, J., JUMPER, E., ERCOLINE, W., Appl. Opt. 1984, 23, 2244-2270.

15. CARTER, G., in Archaeological Chemistry-III: Lambert, J.B., Ed., Advances in Chemistry 205; American Chemical Society: Washington DC, 1984; pp 425-446.

16. LAVOIE, G., LAVOIE, B., ADLER, A., Shroud Spectrum Inter. 1986, 20, 3-6.

17. ADLER, A., SCHWALBE, L., Shroud Spectrum Inter. 1991, 42, 7-15.

\section{NOTE}

An inadvertence on the part of Adler, who knew very well, at least since 1982, that the patches are sewn *into* the backing cloth; the fact is one of the major problems in examining the Shroud. The nuns who repaired the cloth in 1534 wrote an explicit report: "After dinner, the embroiderer brought the wooden frame to stretch the Holland cloth on which one was to place the Holy Shroud; after two hours, the cloth was fixed on the loom and we laid out the precious Holy Shroud upon it and basted all around. His Highness came (other dignitaries) before we had begun to put the patches on the places where the fire had damaged it; ..." The complete text is published in Spectrum \# 2, March 1982, (D.C.). 